Spotts, R.A. and L.A. Cervantes, 1986, Populations, pathogenicity, and benomyl resistance of Botrytis spp., Penicillium spp., and Mucor piriformis in packinghouses. Plant Dis. 70:106-108.

Sugar, D., R.G. Roberts, R.J. Hilton, E.E. Sanchez, and T.L. Righetti. 1990. Effects of fruit nutrient management and postharvest yeast application on fungat decay in pear, Phytopathology 81:1163,

Tronsmo, A. and J. Raa. 1977. Antagonistic action of Trichoderma pseudokoningii against the apple pathogen Botrytis cinerea. Phytopathol, Z. 89:216-220.

Utkhede, R.S. and P.L. Sholberg. 1986. In vitro inhibition of plant pathogens by Bacillus subtilis and Enterobacter aerogenes and in vivo control of two postharvest cherry diseases. Can. J. Microbiol, 32:963-967.
Willett, M., E. Kupferman, R. Roberts, R. Spotts, D. Sugar, G. Apel, H. Ewart, and B. Bryant. 1989. Integrated management of postharvest diseases and disorders of apples, pears, and cherries. Postharvest Pomol. Nwsl. 7:1-14. Washington State Univ. Ext. Serv., Pullman,

Williamson, M.A. and N.J. Fokkema. 1985. Phyllosphere yeasts antagonize penetration from appressoria and subsequent infection of maize leaves by Colletotrichum graminicola. Neth. J. Plant Pathol. 91:265-276.

Wilson, C.L. and M.E. Wisniewski, 1989 Biological control of postharvest diseases of fruits and vegetables: An emerging technology. Annu. Rev. Phytopathol. 27:425-441.

Wisniewski, M., C. Wilson, and W. Hershberger. 1989. Characterization of inhibition of Rhizopus stolonifer germination and growth by Enterobacter cloacae. Can. J. Bet. 67:2317-2323.

\title{
Genetic Manipulation of Plants to Improve Postharvest Disease Resistance
}

\author{
Mark S. Mount and Phyllis M. Berman \\ Department of Plant Pathology, Fernald Hall, University of Massachusetts, Amherst, MA 01003
}

We "mature" plant scientists over the age of $\mathbf{3 5}$ have had the pleasure of watching science fiction turn into science fact over the years. We have gone from slide rules to computers and from biology at the microscopic level to biology at the molecular level. We have not only learned from the mistakes of the past, we are the ones that made them. Our experience has taught us to be cautious and ecologically aware. However, at the same time, we understand that few things in science are impossible, and that innovations, even some seemingly bizarre, must be tried for progress to occur. Ten years ago, we might have laughed at the scientists who theorized that they could actually blast DNA into plants by shooting them with a "gene gun." Today, their success is part of this contribution.

After a brief introduction, describing what transgenic plants are and why the technology is important, this contribution will be divided into two sections. The first, which we call "State-of-the-Art," briefly summarizes some of the current technology involved in genetic engineering of plants. In the second section, "Designing the Future," we will speculate on possible avenues that transgenic plant research might take regarding postharvest disease management.

\section{What is a transgenic plant?}

A transgenic plant contains foreign DNA within its genome. The exogenous DNA, which was introduced artificially via genetic engineering techniques, must be able to be passed on through the plant's germline. This implies actual incorporation of the foreign DNA into the plant's nuclear material. However, we will also use the term "transgenic" to imply any stably inherited foreign genetic material in plants, whether the exogenous DNA has integrated into the nuclear genome or not. One example of the latter might be a plant infected with an altered DNA virus, which remains independent of the plant's nuclear material. However, the foreign gene will be expressed. It is also possible to genetically engineer a plant, even if no foreign DNA is involved. For example, a plant might be artificially manipulated to produce, over-produce, or not produce one of its own proteins by specifically mutating the gene's endogenous control mechanisms. Such a bioengineered plant technically may not be "transgenic," but the end result is an inheritably altered germline. For the purpose of this article, we will not specifically distinguish bioengineered, genetically engineered, or transgenic.

\section{Why create disease-resistant transgenic plants?}

Very simply, creating plant cultivars with inheritable genes for disease resistance is ultimately the most environmentally sound strategy for disease management (Mount and Berman, 1988). Reducing the amount of chemicals applied to crops for disease control certainly makes economic sense too. Altering the genetic make-up of plants for desired traits such as improved yield, increased size, hardiness, disease resistance, etc., is certainly not a new concept. Classical breeding has always provided, and continues to provide, new plant varieties having desirable characteristics. Even though advances in plant tissue culture techniques have certainly helped the science of plant breeding, the process can be too slow, and too inexact. Often, pathogens can mutate too quickly for classical breeding of disease-resistant plant varieties. Bioengineering offers a better shot at keeping one step ahead of the pathogens. New plant varieties with greater disease resistance could be developed more rapidly than via classical methods. Also, it maybe possible to simultaneously add multiple, diverse resistance genes to one plant variety. In addition, transgenic plant technology allows for a wider genetic diversity. Only through bioengineenng could beneficial genes from bacteria, fungi, viruses, or different species of plants be introduced into a plant's germline. But, and this is a very crucial "but," it is important not to rely on only one method of disease control for any particular plant crop. Transgenic plants should be viewed as one component of an "integrated" disease control strategy. This is especially true for postharvest diseases, to be detailed later.

\section{STATE-OF - THE - ART}

\section{Transformation methodology}

Although some transgenic plants with desirable traits and immediate marketable value have been successfully constructed (Council on Scientific Affairs, 199 1; Gasser and Fraley, 1989; Grierson and Covey, 1988; Miki et al., 1990; Old and Primrose, 1989), methodologies are still only in the "toddler" stages, and thus are still far from mature. In the long run, when the techniques are perfected, creating transgenic varieties from almost any plant species will be a "cookbook" routine. For now, at this early trial-and-error stage of experimentation, many problems still must be overcome, and several factors must be taken into consideration when designing a plant genetic engineering scheme. Luckily, with each new advancement in molecular biology techniques, the methodology for bioengineenng plants seems to take a quantum leap.

To construct a transgenic plant, a suitable cell line (whole plant, intact tissue, cultured cells, etc.) to receive the exogenous nucleic acid should be determined, then a methodology for DNA transfer can be chosen. Currently, there are several techniques being attempted, with various degrees of success. Again, there is no consistent, universal procedure that can be applied to all plant species.

Plant cell recipients. Knowing the limitations of the target plant species is very important when choosing a recipient cell line. Is it a dicot or monocot? Can the plant be propagated vegetatively? If the 
plant flowers, can pollen be isolated easily and stored? Can callus tissue or protoplasts be generated, and can whole plants be regenerated from the tissue culture? Is whole plant regeneration possible via meristem culturing? The answers to these questions are important when choosing a methodology for introducing foreign DNA into a plant.

Whole plants or intact plant tissue (i.e., explant tissue, meristem tissue, leaf disks, etc.) is certainly the easiest and most economical recipient for genetic engineering studies. Whole plants can be infected with genetically altered plant viruses (Old and Primrose, 1989). Also, if the plant is dicotyledonous, bioengineering using Agrobacterium tumefaciens (AT) maybe possible (Goodman et al., 1987). If the plant is a monocot, AT is most likely inappropriate, but biolistics or microinjection may be possible for transferring DNA to the plant tissue. we will briefly detail DNA transfer methodology in following sections.

Often, plant tissue culture cells are successful recipients for exogenous DNA. Callus cultures can be formed by isolating living plant tissue cells and propagating them on a complex and complete solid medium. The tissue culture cells remain walled, but become undifferentiated through subsequent divisions. Walled plant cells also can be propagated in liquid suspension media. Exogenous DNA can be introduced into walled cells via AT, biolistics, or microinjection (Goodman et al., 1987). Unwalled cells, called protoplasts, can be generated "from whole-plant tissue, callus, or suspension cultures. Enzymes are used to dissolve the plant cell walls, and isotonic solutions keep the protoplasts from bursting or shrinking. Protoplasts sometimes can be regenerated back into whole plants. At the protoplasm stage, DNA can be introduced by electroporation, liposome or protoplasm fusion, or microinjection. Protoplasts as recipients have many limitations. First, tissue culturing is time consuming, tedious, and expensive. Second, tissue culturing is still not possible for many plant species. Third, plant regeneration from protoplasts is difficult, or not currently possible for many plant species, such as cereal crops. Third, somaclonal variation can sometimes arise from plant regeneration of tissue culture cells (Yeomann, 1986).

Our personal favorite for a potential foreign DNA recipient is pollen. Not only is pollen apparently susceptible to transformation with DNA, via microinjection and electroporation, but, unlike protoplasts, there is no need to induce whole-plant regeneration (AbdulBaki et al., 1990; Hess and Dressier, 1984; Luo and Wu, 1988). The pollen itself is the natural DNA delivery system. Collecting and storing pollen is not nearly as expensive or labor intensive as tissue culture. However, pollen from many plant species does not store well, and decreased viability after genetic manipulation can cause further problems (D. Mulcahy, Univ. of Massachusetts, Amherst, personal communication). In addition, if transgenic pollen cannot be crossed into an identical genetic background, further breeding will be required to stabilize variety improvement.

Agrobacterium tumefaciens. The most successful DNA transfer technology to date uses the phytopathogenic bacterium Agrobacterium tumefaciens (Smith and Townsend), causal agent of crown gall disease (Gheysen et al., 1991; Herrera-Estrella et al., 1990; Klee et al., 1987; Old and Primrose, 1989; Ream, 1989; Walden, 1989). The disease is characterized by formation of undifferentiated tumors (or galls) on a wide variety of plants. Virulence loci on the bacterial chromosome control binding the Agrobacterium to wounded plant cells. The in vivo oncogenic transformation occurs when certain AT genes on a plasmid are transferred directly into susceptible plant cells. These plasmid genes are incorporated into the plant genome, resulting in tumor proliferation even in the absence of the bacterium. Along with uncontrolled cell development, the tumor cells synthesize unusual amino acid derivatives termed "opines" that the AT can use as a C/N source.

Most of the elements necessary for this "trans-phylum" DNA exchange are contained on the AT tumor-inducing plasmid termed the "Ti" plasmid. Located on this closed-circular, nonchromosomal DNA are genes for tumor induction (at the T-DNA region), plant opine synthesis (including nopaline or octopine) and bacterial opine catabolism, conjugative plasmid transfer (bacteria to bacteria), and plasmid transfer and integration into the plant genome (the T-DNA and virulence gene regions). Phenolic compounds from wounded plant tissue, such as acetosyringone and hydroxyacetosyringone from tobacco (Nicotiana tabacum L.), are signal molecules for activating the virulence (vir) region of the plasmid (Old and Primrose, 1989). This activation allows the transfer and integration process to begin. The TDNA region (which includes opine synthesis genes), with its directly repeated right and left borders, actually integrates into the plant genome and causes tumors via phytohormone production.

The Ti plasmid's ability to direct illegitimate recombination of the T-DNA into plants has led to widespread exploitation of grobacterium, the Ti plasmid, or both for use in plant bioengineering. The T-DNA region can be disarmed, rendering the plasmid nononcogenic, but it still retains the ability to integrate and synthesize opines. Through genetic engineering, the original Ti plasmid has been "trimmed" down to only absolutely essential functions, allowing more room for cloning exogenous DNA. In fact, a "binary" vector system has been developed by splitting the necessary genes into two smaller plasmids, allowing for even more cloning space. Also, appropriate screening genes, such as antibiotic resistance and promoters, have been added, and we will detail these in following sections.

Agrobacterium tumefaciens is usually the delivery system for incorporating Ti plasmid constructs into plant cells. Whole plants, plant tissues, or tissue culture cells of dicotyledonous plants can be readily infected with Ti plasmid constructs using AT. Progress can be monitored by expression of screening genes or reporter genes, and by opine synthesis.

In general, monocotyledonous plant species are not susceptible to DNA exchange by AT. However, many attempts have been made to force expression of the $\mathrm{Ti}$ plasmid in nonhost plants. Wounded monocots do not produce the phenolics necessary to induce vir gene expression; therefore, Schafer et al. (1987) preinduced AT with potato (Solarium tuberosum L.) wound extracts before trying to infect yam [Dioscorea esculentum (Lour.) Burk.], a monocot. Gall tumors that contained T-DNA were formed, which demonstrates the feasibility of using AT for monocots. However, other monocots that have been transformed with the Ti plasmid synthesize opines, but have no tumors. Fromm et al. (1985) showed that, while both monocots and dicots could use a plant viral promoter [cauliflower mosaic virus $(\mathrm{CaMV})]$, only dicots could express genes efficiently with the nopaline synthetase (nos) promoter from AT. Although there have been a few isolated reports of AT-transformed monocots (Gasser and Fraley, 1989), little progress has been made using AT on economically important monocotyledonous crops, such as cereals.

Protoplast fusion. If protoplasts can be isolated from a particular plant tissue, and, subsequently, whole plants can be regenerated, then several current DNA transfer methods may be useful for constructing transgenic plant varieties.

Cell membranes of unwalled protoplasts can be conditioned with ions or polyethylene glycol (PEG) to allow uptake of naked DNA (Grierson and Covey, 1988). However, transformation frequencies are traditionally low using this method. PEG-conditioned cell membranes also allow protoplasm fusion in mixed populations of plant cell suspensions. This procedure can permit genetic mixing of species that may not normally cross (Puite et al., 1987). Applying electrical fields may enhance the fusions, but either way, the frequency of transformation is still low (Power et al., 1988). Also, because some cell lines regenerate plants with more than one set of chromosomes, some bizarre-looking crop specimens have been noted. Spheroplast of whole bacteria containing cloned DNA on plasmids can be fused to protoplasts (Power et al., 1988). Protoplasm fusion with fungal spheroplasts has also been accomplished (Puite et al., 1987). A more controlled fusion coats specifically desired exogenous DNA in a liposome "capsule" that can be "melted" into protoplasm membranes using PEG (Antonelli and Stadler, 1990; Deshayes et al., 1985; Draper et al., 1986). Liposome fusion can also be used to transport macromolecules across membranes of germinating pollen tubes ( $\mathrm{Gad}$ et al., 1988).

Electroporation. Electroporation of naked plasmid or chromosomal fragment DNA into protoplasts or pollen is becoming an increasingly popular and successful experimental procedure (AbdulBaki et al., 1990; Fromm et al., 1986; Mishra et al., 1987; Saunders et al., 1989; Shigekawa and Dower, 1988; Tada et al., 1990). Applying 
a controlled electrical field to exposed membranes causes the membranes to become polarized, thus creating a voltage potential across the membrane. At a certain level, the membranes will breakdown in small areas, which increases permeability to exogenous DNA (or other macromolecules). The "holes" in the membrane usually self-repair shortly after exposure to the electrical field. However, there is a critical electrical threshold level, and beyond that point, the cells are permanently "cooked" and of no use for cloning. Commercial electroporation apparatus can be purchased, or homemade equipment can be designed (Berman et al., 1987). Again, we prefer cell-walled pollen, which is easier to handle than protoplasts, as a recipient cell line. Germinating pollen, with its exposed germination tube membranes, has been used in several successful electroporation studies (Abdul-Baki et al., 1990; Mishra et al., 1987). However, finding the proper conditions for electroporating a previously untried cell line can be a long, trial-anderror process, sometimes with no success.

Microinjection. With the proper equipment, pollen, as well as other plant cells, can be microinjected directly with exogenous macromolecules (Crossway et al., 1986; Grierson and Covey, 1988; Miki et al., 1987; Potrykus, 1989; Puite et al., 1987). Both chromosomal fragments and plasmids can be transferred this way. Injecting individual cells without destroying them can be difficult and tedious. Although microinjection is used with some frequency for animal cell lines, this method has not been as successful for plant materials.

de la Pena et al. (1987) performed a different kind of pollen microinjection. Intact plants, not isolated, individual pollen cells, were used. Immature rye (Secale cereale L.) floral tillers were injected with exogenous DNA, and that DNA was taken up at the "prepollen" stage. Only two out of 3000 seedlings generated using pollen from these injected plants showed foreign DNA incorporation. Our laboratory is working on ways to improve the uptake frequency for this method.

Biolistics. In the early 1980s, John Sanford and colleagues at Cornell Univ. began shooting onion (Allium cepa L.) cells with tungsten particles (Sanford, 1988). The cells remained viable and even actively transported the particles via the cytoplasmic stream. Next, plant viral RNA was bound to the tungsten, and then the coated particles were shot into plant tissue. The viral RNA was expressed in up to $40 \%$ of the penetrated cells. Thus, a new method for introducing nucleic acids into plant cells was born, and a new name, "biolistics," was coined to describe it. Biolistic particle delivery system equipment is now commercially available. This system, because it does not require protoplasts as recipients, offers many advantages and much hope for bioengineering economically important crops. Tobacco, soybean [Glycine max (L.) Merr.], and corn (Zea mays L.) transgenic plants have been created using this method (Christou et al., 1989; Klein et al., 1988, 1989; Tomes et al., 1990), and transient expression of foreign DNA in many other plant species has been noted.

Virus vectors. The last method we will discuss is use of plant viruses. From the earliest notion of plant bioengineering, plant DNA and RNA viruses were obvious choices for possible DNA vectors (Old and Primrose; 1989; Walden, 1989). Viruses have natural access for direct entry of genetic material into plant cells, and almost every plant species is susceptible to at least one plant virus. Viral genes can be expressed in plant cells, and many viruses can spread throughout the plant via the vascular system. However, several limitations to cloning with viruses soon were encountered. Many plant viruses require insect vectors for infection. Viral nucleic acids most often do not integrate into the plant genome. Some viruses are difficult to disarm and still remain infective. Others, like CaMV, do not have large, nonessential areas on their DNA and, therefore, have little cloning room (the total amount of DNA can be no larger than the original CaMV DNA). CaMV was thought to have the most potential as a DNA vector, but little success has been noted. However, initial studies so well scrutinized CaMV DNA organization that an important discovery was made. The $35 \mathrm{~S}$ promoter region of CaMV can be successfully expressed in a wide variety of plants and has been cloned onto other DNA vectors for use with a different DNA transfer method (Benfey and Chua, 1990). We will explain more about promoters in a following section. Other viruses still being considered, or used with some success, as exogenous DNA or RNA vectors include geminivirus, barley stripe mosaic virus, brome mosaic virus, and tobacco mosaic virus (TMV) (Joshi et al., 1990; Old and Primrose, 1989). We should also mention that some geminiviruses have been incorporated on the Agrobacterium Ti plasmid, and the hybrid plasmid has been used to infect plant cell hosts (Old and Primrose, 1989; Potrykus, 1989). This "agroinfection" is an important development because it can be used to circumvent the insect carriers usually necessary for geminivirus infection.

\section{Genes for transfer}

Target genes. Desirable target genes for creating useful transgenic plants usually are isolated from plant viruses, bacteria, fungi, or other plants, depending on the traits desired. For example, the TMV viral coat protein, when cloned into tomatoes, confers resistance to TMV infection (Abel et al., 1986). It is now also possible to create artificial mRNA species with sequences that are "antisense" to the mRNA of a specific gene normally expressed in plants (Green et al., 1986). If the antisense RNA is present and binds the sense mRNA as it is being made, the gene product is not synthesized. The sense/antisense hybrids may block mRNA passage to the cytoplasm, enhance RNA turnover, and/or interfere with RNA translation (Walden, 1989). Therefore, endogenous plant mRNA species can be turned off by cloning in the specific antisense sequences. We will detail how this approach can be effective for postharvest disease resistance. Because mRNA from phytopathogenic bacteria and fungi are confined within their own membranes, antisense cloning would not be directly effective. However, it maybe possible to use anti sense mRNA to turn off compounds that the plant elicits in response to bacteria or fungi (i.e., the vir genes of AT are turned on by plant phenolics). Also, antisense mRNA can be used effectively against viral diseases. An anti sense construct to potato leafroll virus coat protein was cloned into potatoes, and the transgenic potatoes exhibited resistance to potato leafroll virus (Kawchuk et al., 1991). However, with a few minor exceptions, viruses are not considered postharvest pathogens, so we will not discuss viral disease control further.

We do wish to impress that selecting a useful target gene for pathogen resistance is not a simple matter. A thorough understanding of the pathogen, the host, and the host-pathogen interaction is required. This information only can come from a multitude of genetic and physiological experiments. In fact, when the methodology for creating transgenic plants has been perfected, the slowest part of the process will probably still be selecting a beneficial target gene.

Promoters. Once safely and stably transferred into the plant cell, a target gene will only be expressed if the plant can recognize the gene's transcriptional regulatory factors. Some genes of bacterial origin, such as the gene for kanamycin resistance, may have no problem in the plant cell, regardless of which orientation the gene incorporates (de la Pena et al., 1987). This is certainly not true for other prokaryotic genes, including the reporters. Again exploiting the Ti plasmid, the nos promoter from the nopaline synthetase gene has been fused to target genes and successfully expressed in dicots, but not as well in monocots (Fromm et al., 1985). The 35S promoter from CaMV has been useful for both monocots and dicots. The alcohol dehydrogenase promoter from maize has been successfully tested for expression in tissue other than corn (Wang et al., 1988). Use of inducible or tissue specific promoters can be used to more accurately control target gene expression (Schell and Vasil, 1989). Expression of many plant genes can be induced by factors such as light, temperature, physical stress, wounding, chemicals, and pathogen attack. The regulatory elements on these genes may be exploited for use with target genes (Schell and Vasil, 1989). This way, the target gene could be expressed only at an appropriate condition, rather than constitutively (Giovannoni et al., 1989). Similarly, plant gene regulators that are only expressed at specific developmental stages or only in specific tissues, i.e., pollen, tubers, and roots also may be of great value for bioengineering (Edwards and Coruzzi, 1990). Postharvest disease control presents unique problems that may be solvable if the correct promoters are used.

Screening genes. How can you be sure that the target gene, with its proper promoter, which you have painstakingly delivered to the plant cell, is actually in the cell and will be expressed in vivo? To see if any 
part of the system is being expressed, construct a vector with everything necessary for monitoring DNA uptake and expression using screening and reporter genes.

Screening genes can be used to confirm vector expression and, at the same time, eliminate the vast majority of recipient cells that did not receive any exogenous DNA. Resistance genes to antibiotics such as kanamycin, gentamicin, chloramphenicol, trimethoprim, or hygromycin are extremely useful for the selection process (Council on Scientific Affairs, 1991; Schell and Vasil, 1989; Waldron et al., 1985). Use of antibiotic resistance markers must be closely scrutinized, especially if the transgenic crop is consumable. There is no evidence to date that the resistance genes from ingested plant materials are transposable to other microorganisms. The possibility also exists that transposition of resistance genes to microorganisms in the field, including attacking pathogens, might occur in nature. Therefore, controlled laboratory and field testing is essential before transgenic plants are marketable.

Reporters. Reporter genes are used not only to confirm that exogenous DNA is being expressed in the new host, but also, to some extent, to quantitate how well the system is working. Reporter genes can be used to detect opine synthesis carried on Ti plasmid derivatives. However, most reporter genes code for easily assayed enzymes that are not normally produced by the recipient cell. The assay usually entails adding the enzyme's substrate, allowing the reporter enzyme to act on the substrate, and then quantitating the final reaction products. Three popular reporters used for transgenic plant studies ar $\beta$ - glucuronidase, chloramphenicol acetyltransferase, and luciferase (LUX) (Doemer et al., 1990; Fromm et al., 1985; Jefferson, 1987; Ow et al., 1986). The LUX gene reaction product confers a detectable fluorescence. Ow et al. clearly demonstrated LUX gene expression in transgenic tobacco. Reporter genes are often used to test the feasibility of using a particular vector system before cloning any target genes on the vector. They can be used to confirm the expression, location, and inducibility of the transferred reporter enzyme activity in planta. We should note that, while reporter genes are useful as study tools, they are not necessary for expression of a target gene and, therefore, can be ultimately removed from the vector to allow more cloning space.

\section{Examples}

A complete vector system. There are several good examples of wellconstructed vector systems with all the proper elements necessary for creating transgenic plants. One example is a Ti plasmid binary system created in Clarence Kado's laboratory (Zyprian and Kado, 1990). The integrating plasmid has both nos and 35S CaMV promoters; carries hygromycin, kanamycin, neomycin, and gentamicin resistance genes; and contains several unique cloning sites for foreign DNA. Because of its multiple promoters, screening genes, and target gene cloning sites, this system should be applicable to many plant species.

Transgenic plant species. Some transgenic plants are at the fieldtesting stage, and some are even ready to be marketed. TMV-resistant transgenic tobacco has been successfully field-tested (R. Beachy, personal communication). Calgene has had promising field results with an antisense polygalacturonase tomato (Lycopersicon esculentum L.) that has increased shelf life (Kramer, 1990). Several companies are reporting breakthroughs in genetically transforming corn (Cutler, 1991 ). Both insect-resistant and herbicide-resistant transgenic plants have been tested (Council on Scientific Affairs, 1991). There are many more examples of field-tested transgenic plants, and even more that look promising at the tissue culture and reporter gene stage. We are sure that you will be reading about them soon.

\section{DESIGNING THE FUTURE}

\section{Postharvest problems}

Postharvest diseases. Now, how can we relate all of this molecular technology to postharvest situations? The nature of postharvest diseases was discussed in the previous contributions. It is through the knowledge and understanding of postharvest disease etiology and physiology that we can develop genetic strategies for disease management. We know several factors that likely will help us develop new resistant transgenic plants. For example, latent infections tell us that the potential pathogenic organism may be present in asymptomatic tissues. Can we prevent the original inoculum from establishing in the tissue or from proliferating later on? We also know that wounding and other environmental conditions can trigger a disease response. Can we devise a control scheme that is specifically turned on by wounding? Can we genetically alter the plant to be more physically resistant to wounding? We know that insects may disseminate organisms or cause injury to harvested products, thereby predisposing plant tissue to disease. Will transgenic plants with insect resistance also be more resistant to postharvest disease? We know that cell-wall-degrading enzymes elicited by pathogenic microorganisms are responsible for plant deterioration. Can we create a plant that turns off the pathogen's cell-wall-degrading enzymes? Would altering the plant's natural ripening process help in postharvest disease resistance?

Postharvest pathogens. Postharvest disease can be due to abiotic factors, such as preharvest nutritional deficiencies, or to improper temperatures before or after harvest. These problems can be handled without involving molecular genetics, although cloning "antifreeze" genes is certainly feasible. However, we will concentrate on controlling diseases caused by biological pathogens. Bacteria and fungi are potential postharvest pathogens. Transgenic plants that are specifically designed to control fungal damage may not be appropriate for bacteria and vice versa. But the concepts for designing a control strategy may be similar. The pathogen is present, the conditions for attack become ideal, the plant responds to attack, the pathogen responds to the plant's response either negatively or positively. At each step, the plant might have been premanipulated for proper resistance. We emphasize that postharvest problems are often due to preharvest inoculation with potential pathogens. Wounding, often by harvesting, triggers latent microorganisms to become pathogenic, if the right conditions exist. Improper crop storage temperatures and humidity constitute ideal conditions for pathogen proliferation. Bacteria and fungi in the milieu also can capitalize on wounding and environmental conditions for postharvest tissue damage, at any time before or after harvest. How might we proceed in logically developing transgenic plants for resistance to postharvest decay organisms or the products that they elicit?

\section{Developing postharvest disease-resistant transgenic plants}

Antibiosis. One strategy for controlling bacteria or fungi would be to clone genes for antibiotics, or other generalized antibiosis compounds. Nikkomycin, an antibiotic produced by Streptomyces tendae (Ettlinger, Corbaz, \& Hunter), has been shown to be effective against fungi (Kinzel, 1989). The compound tentatively has been proven nontoxic in tests with laboratory mice and, therefore, maybe useful for consumable crops. Several other natural antibiotics with proven effectiveness against bacteria or fungi exist. Transgenic plants with genes for antibiotic production could prevent initial inoculation of plant tissue with pathogenic organisms. However, caution is always necessary with widespread use of antibiotics. The pathogen, and even other unrelated microorganisms, could develop resistance to the antibiotic. Perhaps tissue-specific, stage-specific, or specifically inducible promoters would be useful for this situation. Antibiotic production could then be limited in quantity or confined. Maybe antibiotic production only during early plant developmental stages could "self-sterilize" seedlings, rendering edible portions of the mature plant both pathogen and antibiotic free.

Sources for other novel antibiosis genes may come from plants themselves, or from the numerous microorganisms now being studied for use as biological control agents. If the antibiosis is due to a compound with isolatable genes, the genes may be valuable for bioengineering plants. The bacterium Serratia marcescens Bizio, and many other microorganisms, produce a variety of chitinases (Jones et al., 1986; Ordentlich et al., 1988; Roberts and Selitrennikoff, 1988; Shapira et al., 1989; Vyas and Deshpande, 1989). Chitinases have been effective against fungi, whose cell walls contain chitin as a major structural component. As a bonus, chitinases also may have a deleterious effect on insects and nematodes. It seems reasonable that if the right exogenous chitinase gene were introduced into and expressed in 
a plant, then the plant could arrest fungal development. Lund et al. (1989) demonstrated that cloned bacterial chitinase could be expressed in and secreted by transgenic tobacco. However, pathogen resistance was not addressed in Lund's report. In our own preliminary work, we showed that chitinases from several natural bacteria react differentially in vitro to various fungal species. Therefore, it is extremely important to identify a particular chitinase gene that is effective toward the pathogens of interest. Once this gene is identified, the desired transgenic plant can be created through molecular manipulation. It is possible to visualize incorporating several chitinase genes at once to be effective against a variety of fungi, thus achieving a more complete resistance mechanism. Here again, specific promoters could be used to control chitinase production. Perhaps these genes could be produced constitutively, or rapidly produced under wounding or bruising conditions. Plants also can produce chitinases along with other compounds induced by pathogen attack (Irving and Kuc, 1990; Kombrink et al., 1988; Legrand et al., 1987; Linthorst et al., 1990; Roberts and Selitrennikoff, 1988). Broglie et al. (1991) created transgenic tobacco that constitutively expressed a bean chitinase gene. These plants were resistant to the fungus Rhizoctonia solani (Kühn). Overproduction or constitutive production of a plant's own endogenous chitinases maybe effective for disease resistance as well.

Other inducible antimicrobial compounds normally produced by plants might also be exploited for bioengineenng (Bowles, 1990; Ye et al., 1990). High peroxidase activity has been implicated in phytopathogen resistance (Mohan and Kolattukudy, 1990). Also of interest may be hydrolyses, proteinases, and other pathogen-defense-related compounds induced in response to pathogen attack. In addition, anew family of plant antifungal proteins has been discovered. The protein zeamatin is among this group (Vigers et al., 1991). These compounds act by changing fungal membrane permeability. Cloning antibiosis protein genes and antibiotic genes into plants is the subject of several current studies.

Regulating pathogen gene products. Another strategy for bioengineering plants with postharvest disease resistance would be to clone genes having products that would not kill pathogens, but rather disarm their ability to cause disease. Without a battery of plant cell-walldegrading enzymes, bacteria and fungi could not cause extensive postharvest deterioration. Many Erwinia species have multiple, genetically independent pectolytic enzymes. To clone a plant with specific resistance to all of these enzymes would be difficult. However, Chatterjee et al. (1994) detailed the discovery of regulatory genes that are necessary for cell export of several major bacterial cellwall-degrading enzymes produced by the postharvest pathogenErwinia carotovora (Jones) (Murata et al., 1991). There is evidence that this Aep (activation of extracellular enzyme production) regulatory gene system may be controlled by regulatory proteins of its own. How appropriate if it were possible to clone a repressor gene, or a gene that would repress an activator of the Aep genes in plants! How nice if expression of this cloned Aep regulator could be made woundinducible ! If successful, the implications of this regulatory system to the future of pathogen-resistant transgenic plant production would be tremendous. A greater understanding of the Aep system is necessary to evaluate the feasibility of its use in transgenic plants.

Resistance to wounding. Yet another strategy for bioengineering postharvest disease-resistant plants would be to improve plant tissue by increasing wound resistance, or enhancing wound response. Some approaches might be similar to those of classical plant breeding, such as cloning for production of melons or fruits with tougher outer skins. Another tactic might involve enhancing wound-induced healing compounds to shorten the amount of time that the damaged tissue is vulnerable to pathogen attack. Manipulating the plant's woundinduced pathogen resistance compounds, as discussed in the antibiosis section, may also apply here.

Because insects can damage harvested crops and, at the same time, disseminate pathogen inoculum, insect-resistant plants may be of value for both pre- and postharvest problems. As discussed previously, chitinases may be useful. A model system proven to be effective against a particular insect pest is the BT toxin from the bacterium Bacillus thuringiensis (Berliner), which is effective against several insect species. Cloning the BT toxin gene has already produced insect- resistant transgenic plant varieties (Delannay et al., 1989; Grierson and Covey, 1988). Resistance genes effective against other insect pests most likely exist.

Controlling ripening. Controlling the ripening process in plants also may be a way to prevent postharvest losses. Because this involves manipulating the plant's own internal biological clock, using anti sense RNA is an appropriate bioengineering method. Plant enzymes and hormones involved in ripening are the most logical targets for genetic manipulation. Using a pleotrophic mutation, rin, that blocks many aspects of the ripening process, Giovannoni et al. (1 989) demonstrated that tomato polygalacturonase (PG) had a major role in degrading cell wall polyuronides, but little effect on fruit softening or color development. This study indicated that PG repression might be useful in increasing fruit shelf life. Bioengineenng this enzyme has been accomplished with tomatoes (Kramer, 1990; Kramer et al., 1990; Smith et al., 1988). Antisense RNA to the mRNA of the tomato's own PG was introduced into the plant. The resulting produce has a longer shelf life, and "neither flavor nor texture has been compromised. Because the tissue does not soften at the same rate as normal tissue, the fruit should have increased resistance to postharvest pathogen attack. Transgenic tomatoes with an antisense gene to ethylene, a hormone involved in ripening, have also been developed (Hamilton et al., 1990). The tomato studies offer a model system that should be readily applicable to other crops.

\section{CONCLUDING REMARKS}

\section{Problems to overcome}

All of these approaches to creating transgenicplants with postharvest disease resistance are, in the long run, certainly feasible. In fact, the number of transgenic plants generated with marketing potential is increasing each year. However, we again emphasize that routine use of genetic engineering for plants is still only a prospect. Once a bank of specific promoters exists, it will be easy to custom-design gene expression in plants. For now, that bank is very low on deposits, and promoters are not easily isolated. Selecting effective target genes requires many background genetic and physiological studies on the target gene, the pathogen, and the recipient plant. Transformation frequencies for all methodologies need to be increased. Even if the best vector systems are used and expressed successfully, there is always the possibility that your target gene was inserted backwards, making it impossible to read. These nonusable clones may dilute the frequency of successful clones obtained in a given experiment. Even if your gene is inserted correctly and read properly, the gene product may be useless. Proteins termed "chaperones" make other specific proteins functional by folding them into the correct tertiary structure-no chaperone, no usable activity (Ellis, 1990; Newbury, 1985). Does your target protein require a chaperone that must be cloned too? How about a specific protease that cuts out superfluous introns in your target gene, does your gene require one of those? If yes, will it then be necessary to isolate mRNA to make complementary DNA for cloning? Does your target gene render the plant disease-resistant, but totally inedible or aesthetically horrifying? Our point is clear. There are still many problems to overcome, and a lot of work to be done; but the potential benefits are certainly worth the effort.

\section{Integrated disease management strategies}

In terms of relying on only transgenic plant technology to solve all plant disease problems, it is never prudent to put all of your eggs in one transgenic basket. This is certainly not the time to think about discontinuing the wild germplasm banks. This genetic information is priceless, irreplaceable, and will always be essential. Biological control strategies other than transgenic plant technology still need to be pursued. Newer and safer pesticides must still be developed and probably will always be part of a pest management program. The key is to integrate your control methods. We envision starting with a disease-resistant transgenic plant variety; plant it in afield treated with nonpathogenic microorganisms that are biological control agents; when environmental conditions are absolutely ideal for pathogen 
proliferation, apply pesticides if warranted; use care in harvesting; and be prudent about maintaining the proper storage conditions. The final product is bound to be at its best.

\section{Safety}

Finally, we have only briefly mentioned safety issues involved in genetically engineering plants. An entire presentation could describe the safety restrictions that are genuinely necessary before a transgenic plant can be released. We, the scientists, must act responsibly at all times to earn the public trust that will be so important for the future of plant genetic engineering.

\section{Philosophy}

In conclusion, let me say that it is very satisfying to be a "mature" plant scientist; old enough to have had the pleasure of watching the threshold of a dream be constructed, yet still young enough to be able to pass through the doorway.

\section{Literature Cited}

Abel, P.P., R.S. Nelson, B. De, N. Hoffman, S.G. Rogers, R.T. Fraley, and R.N. Beachy. 1986. Delay of disease development in transgenic plants that express the tobacco mosaic virus coat protein gene. Science 232:738-743,

Abdul-Baki, A. A., J.A. Saunders, B.F. Matthews, and G.W. Pittarelli. 1990 DNA uptake during electroporation of germinating pollen grains. Plant Sci. 70:181-190.

Antonelli, N.M. and J. Stadler. 1990. Genomic DNA can be used with cationic methods for highly efficient transformation of maize protoplasts, Theor. Appl. Genet. 80:395-401.

Benfey, P.N. and N-H Chua. 1990, The cauliflower mosaic virus 35S promoter: Combinatorial regulation of transcription in plants. Science 250:959-966.

Berman, P., M. Mount, and G. Lacy, 1987. Electro-transformation of Erwinia carotovora subsp. carotovora. Fallen Leaf Lake Conf. Erwinias, Lake Tahoe, Nev., 17-20 Sept. (Abstr.)

Bowles, D.J. 1990. Defense-related proteins in higher plants. Annu. Rev. Biochem. 59:873-907.

Broglie, K., L Chet, M. Holliday, R. Cressman, P. Biddle, S. Knowlton, C.J. Mauvais, and R. Broglie. 1991. Transgenic plants with enhanced resistance to the fungal pathogen Rhizoctonia solani. Science 254:1194-1197.

Chatterjee, A., H. Murata, J.L. McEvoy, and A. Chatterjee. 1994. Global regulation of pectinases and other degradative enzymes in Erwinia carotovora subsp. carotovora, The incitant of postharvest decay in vegetables. HortScience 29:754-758.

Christou, P., W.F. Swain, N.S. Yang, and D.E. McCabe. 1989. Inheritance and expression of foreign genes in transgenic soybean plants. Proc. Natl. Acad. Sci. USA 86:7500-7504.

Council on Scientific Affairs. 1991. Biotechnology and the American agricultural industry. J. Amer. Med. Assn. 265: 1429-1436.

Crossway, A., J.V. Oakes, J.M. Irvine, M. Ward, V.C. Knauf, and C.K. Shewmaker. 1986. Integration of foreign DNA following microinjection of tobacco mesophyll protoplasts. Mol. Gen. Genet. 202: 179-185.

Cutler, K. 1991. The current state of corn transformation-How is the race developing? AgBiotech. News p. 4.

de la Pena, A., H. Lorz, and J. Schell. 1987. Transgenic rye plants obtained by injecting DNA into young tillers. Nature 325:274-276.

Delannay, X., B.J, LaVallee, and R.K. Proksch. 1989. Field performance of transgenic tomato plant expressing the Bacillus thuringiensis var. kurstaki insect control protein. Biotechnology 7: 1265-1 269.

Deshayes, A., L. Herrera-Estrella, and M. Caboche. 1985. Liposome-mediated transformation of tobacco mesophyll protoplasts by an Escherichia coli plasmid. EMBO J. 4:2731-2737.

Doerner, P.W., B. Stermer, J. Schmid, R.A. Dixon, and C.J. Lamb. 1990. Plan defense gene promoter-reporter gene fusions in transgenic plants: Tools for identification of novel inducers. Biotechnology 8: 845-848.

Draper, J., M.R. Davey, and J.P. Freeman. 1986. Delivery systems for the transformation of plant protoplasts, p. 27 1-307. In: J.M. Yeoman (ed.). Plant cell culture technology. Bet. Monogr. vol. 23. Blackwell Scientific Publications, Boston.

Edwards, J.W. and G.M. Coruzzi. 1990. Cell-specific gene expression in plants. Annu. Rev. Genet. 24:275-303.

Ellis, R.J. 1990. Molecular chaperones: The plant connection. Science 250:954959.

Fromm, M. E., L.P. Taylor, and V. Walbot. 1985. Expression of genes transferred into monocot and dicot plant cells by electroporation. Proc. Natl. Acad. Sci. USA 82:5824-5828.
Fromm, M.E., L.P. Taylor, and V. Walbot. 1986, Stable transformation of maize after gene transfer by electroporation. Nature 319:79 1-793.

Gad, A. E., B-Z. Zeewi, and A. Altman. 1988. Fusion of germinating watermelon pollen tubes with liposomes. Plant Sci. 55:69-75.

Gasser, C.S. and R.T. Fraley. 1989, Genetically engineering plants for crop improvement. Science 244:1293-1299.

Gheysen, G., R. Villarroel, and M. Van Montagu. 1991. Illegitimate recombination in plants: A model for T-DNA integration. Genes \& Development 5:287-297, Cold Spring Harbor Laboratory Press, Cold Spring Harbor, N.Y.

Giovannoni, J.J., D. DellaPenna, A.B. Bennett, and R.L. Fishcer. 1989. Expression of a chimeric polygalacturonase gene in transgenic rin (ripening inhibitor) tomato fruit results in polyuronide degradation but not fruit softening. Plant Cell 1:53-63.

Goodman, R. M., H. Hauptli, A. Crossway, and V.C. Knauf. 1987, Gene transfer in crop improvement. Science 236:48-54.

Green, P.J., O. Pines, and M. Inouye. 1986. The role of antisense RNA in gene regulation. Annu. Rev. Biochem. 55:569-597.

Grierson, D. and S.N. Covey. 1988. Plant molecular biology. 2nd ed. Chapman and Hall, New York.

Hamilton, A. J., G.W. Lycett, and D. Grierson, 1990. Antisense gene that inhibits synthesis of the hormone ethylene in transgenic plants. Nature 346:284-287.

Herrera-Estrella, A., M. Van Montagu, and K. Wang, 1990. A bacterial peptide acting as a plant nuclear targeting signal: The amino-terminal portion of Agrobacterium VirD2 protein directs a $\beta$-galactosidase fusion protein into tobacco nuclei. Proc. Natl. Acad. Sci. USA 87:9534-9537.

Hess, D. and K. Dressier, 1984. Bacterial transferase activity expressed in petunia progenies. J. Plant Physiol. 116:261-272.

Irving, H.R. and J.A. Kuc. 1990. Local and systemic induction of peroxidase, chitinase and resistance in cucumber plants by $\mathrm{K}_{2} \mathrm{HPO}_{4}$. Physiol. Mol. Plant Pathol. 37:355-366.

Jefferson, R.A. 1987. Assaying chimeric genes in plants: The GUS gene fusion system. Plant Mol. Biol. Rptr. 5:4:387-405.

Jones, D. G.J., K.L. Grady, T.V. Suslow, and J.R. Bedbrook. 1986, Isolation and characterization of genes encoding two chitinase enzymes from ,Serratia marcescens, EMBO J. 5:467473.

Joshi, R. L., V. Joshi, and D.W. Ow. 1990. BSMV genome mediated expression of a foreign gene in dicot and monocot plant cells. EMBO J. 9:2663-2669.

Kawchuk, L. M., R.R. Martin, and J. McPherson. 1991. Sense and anti sense RNA-mediated resistance to potato leafroll virus in Russet Burbank potato plants. Mol. Plant-Microbe Interactions 4:247-253.

Kinzel, B. 1989. Nikkomycin-Antibiotic for plants. Agr. Res. p. 19.

Klee, H., R. Horsch, and S. Rogers. 1987, Agrobacterium-mediated plant transformation and its further applications to plant biology. Annu, Rev, Plant Physiol. 38:467-486.

Klein, T. M., M. Fromm, A. Weissinger, D. Tomes, S. Schaaf, M. Sletten, and J.C. Sanford. 1988. Transfer of foreign genes into intact maize cells with high-velocity microprojectiles, Proc. Natl, Acad. Sci. USA 85:4305-4309.

Kombrink, E., M. Schroder, and K. Hahlbrock. 1988. Several "pathogenesisrelated" proteins in potato are 1,3- $\beta$-glucanases and chitinases. Proc. Natl. Acad. Sci. USA 85:782-786.

Kramer, M. 1990, Genetically engineered plant foods: Tomatoes, p. 127-130. In: J. Fessenden MacDonald (cd.). Report 2, agricultural biotechnology, food safety and nutritional quality for the consumer, Natl. Agr. Biotech. Council. Union Press, Binghamton, New York.

Kramer, M., R.A. Sanders, R.E. Sheehy, M. Melis, M. Kuehn, and W.R. Hiatt. 1990. Field evaluation of tomatoes with reduced polygalacturonase by antisense RNA, p. 347-355. In: A.B. Bennett and S.D. O'Neill (eds.). Horticultural biotechnology. Wiley-Liss, New York.

Lamb, C.J. and R.N. Beachy. 1990. Plant gene transfer, Univ. of California, Los Angeles, Symp. Mol. Cellular Biol., New Series. vol. 129,

Legrand, M., S. Kauffmann, P. Geoffroy, and B. Fritig. 1987. Biological function of pathogenesis-related proteins: Four tobacco pathogenesisrelated proteins are chitinases, Proc. Natl. Acad. Sci. USA 84:6750-6754.

Linthorst, H.J.M., L.C. van Loon, C.M.A, van Rossum, A. Mayer, J.F. Bol, J.S.C. van Roekel, E.J.S. Meulenhoff, and B.J.C. Cornelissen. 1990. Analysis of acid and basic chitinases from tobacco and petunia and their constitutive expression in transgenic tobacco. Mol. Plant-Microbe Interactions 3:252-258.

Lund, P., R.Y. Lee, and P. Dunsmuir, 1989. Bacterial chitinase is modified and secreted in transgenic tobacco. Plant Physiol. 91:130-1 35.

Luo, Z.-X. and R. Wu, 1988. A simple method for the transformation of rice via the pollen-tube pathway. Plant Mol. Biol. Rptr. 6: 165-174.

Miki, B. L., V.N. Iyer, and T.J. Reich, 1987. Transformation of higher plant cells by intranuclear microinjection. In: C.E. Green, D.A. Somers, W.P. Hackett, and D.D. Biesboer (eds.). Plant tissue and cell culture. Plant Biol 3:435-446. Liss, New York.

Miki, B. L., H. Labbti, J. Hattori, T. Ouellet, J. Gabard, G. Sunohara, P.J. 
Charest, and V.N. Iyer. 1990. Transformation of Brassica napus canola cultivars with Arabidopsis thaliana acetohydroxy acid synthase genes and analysis of herbicide resistance, Theor. Appl. Genet. 80:449-458.

Mishra, K.P., D.C. Joshua, and C.R. Bhatia. 1987, In vitro electroporation of tobacco pollen. Plant Sci. 52:135-139.

Mohan, R. and P.E. Kolattukudy. 1990. Differential activation of expression of a suberization-associated anionic peroxidase gene in near-isogenic resistant and susceptible tomato lines by elicitors of Verticillium albo-strum. Plant Physiol. 921:276-280.

Mount, M.S. and P.M. Berman. 1988. Biotechnology and plant disease control: Helping nature to help itself, p. 39-43, In: S. Engelstad, W.M. Coli, and J.L. Carlson (eds.). Innovations in pest management. Proc. Integrated Pest Management and Biological Controls. Massachusetts Dept. of Food and Agriculture, Sturbridge.

Murata, H., J.L. McEvoy, A. Chatterjee, A. Collmer, and A.K. Chatterjee. 1991. Molecular cloning of an aepA gene that activates production of extracellular pectolytic, cellulolytic, and proteolytic enzymes in Erwinia carotovora subsp. carotovora. Mol. Plant-Microbe Interactions 4:239-246.

Newbury, H.J. 1985. Some possibilities for genetic engineering of Rubisco, p. 115-142, In: J.H. Dodds (ed.), Plant genetic engineering. Cambridge Univ. Press, New York.

Old, R.W. and S.B, Primrose. 1989. Principles of gene manipulation, 4th ed. Blackwell Scientific Publications, Oxford, U.K.

Ordentlich, A,, Y. Elad, and I. Chet, 1988. The role of chitinase of Serratia marcescens in biocontrol of Sclerotium rolfsii. Phytopathology 78:84-88.

Ow, D.W., K.V. Wood, M. Deluca, J.R. deWet, D.R. Helinski, and S.H. Howell. 1986. Transient and stable expression of the firefly luciferase gene in plant cells and transgenic plants. Science 234: 856-859.

Potrykus, L 1989. Gene transfer to cereals: An assessment. Trends Biotech. 7:269-273.

Power, J. B., M.R. Davey, J.P. Freeman, B.J. Mulligan, and E.C. Cocking. 1988. Fusion and transformation of plant protoplasts, p. 385-401. In: A. Weissbach and H. Weissbach (eds.). Methods for plant molecular biology. Academic, London.

Puite, K.J., J.J.M. Dons, H.J. Huizing, A.J. Kool, M. Koornneef, and F.A. Krens (eds,). 1987. Progress in plant protoplasm research. Proc. 7th Intl. Protoplasm Symp., Wageningen, The Netherlands. Kluwer Academic Publishers, Norwell, Mass.

Ream, W. 1989. Agrobacterium tumefaciens and interkingdom genetic exchange. Annu. Rev. Phytopathol. 27:583-618.

Roberts, R.K. and C.P. Selitrennikoff. 1988. Plant and bacterial chitinases differ in antifungal activity. J. Gen. Microbiol. 134:169-176,

Sanford, J.C. 1988. The biolistic process. Trends Biotech. 6:299-302.

Saunders, J. A., CR. Smith, and J.M. Kaper, 1989. Effects of electroporation pulse wave on the incorporation of viral RNA into tobacco protoplasts. BioTechniques 7:1124-1131.
Schafer, W., A. Gorz, and G. Kahl. 1987. T-DNA integration and expression in a monocot crop plant after induction of Agrobacterium. Nature 327:529531.

Schell, J. and I.K. Vasil (eds.). 1989. Cell culture and somatic cell genetics of plants: Molecular biology of plant nuclear genes. vol. 6. Academic, New York.

Shapira, R., A. Ordentlich, I. Chet, and A.B. Oppenheim. 1989. Control of plant diseases by chitinase expressed from "cloned DNA in Escherichia coli. Phytopathology 79:1246-1249.

Shigekawa, K. and W.J. Dower. 1988. Electroporation of eukaryotes and prokaryotes: A general approach to the introduction of macromolecules into cells. BioTechniques 6:742-751,

Smith, C.J.S., C.F. Watson, J. Ray, C.R. Bird, P.C. Morris, W. Schuch, and D. Grierson. 1988. Antisense RNA inhibition of polygalacturonase gene expression in transgenic tomatoes. Nature 334:724-726.

Tada, Y., M. Sakamoto, and T. Fujimura. 1990. Efficient gene introduction into rice by electroporation and analysis of transgenic plants: Use of electroporation buffer lacking chloride ions. Theor. Appl. Genet. 80:475480.

Tomes, D, T., A.K. Weissinger, M. Ross, R. Higgins, B.J. Drummond, S. Schaaf, J. Malone-Schoneberg, M. Staebell, P. Flynn, J. 'Anderson, and J. Howard. 1990. Transgenic tobacco plants and their progeny derived by microprojectile bombardment of tobacco leaves. Plant Mol. Biol. 14:261268.

Vigers, A.J., W.K. Roberts, and C.P. Selitrennikoff. 1991, A new family of plant antifungal proteins. Mol. Plant-Microbe Interactions 4:315-323.

Vyas, P. and M.V. Deshpande. 1989. Chitinase production by Myrothecium verrucaria and its significance for fungal mycelia degradation. J. Gen. Appl. Microbiol. 35:343-350.

Walden, R. 1989. Genetic transformation in plants. Prentice Hall, Englewood Cliffs, N.J.

Waldron, C., E.B. Murphy, J.L. Roberts, G.D. Gustafson, S.L. Armour, and S.K. Malcolm. 1985. Resistance to hygromycin B. Plant Mol. Biol. 5:103108.

Wang, Y. C., T.M. Klein, E. Fromm, J. Cao, J.C. Sanford, and R. Wu. 1988. Transient expression of foreign genes in rice, wheat and soybean cell following particle bombardment. Plant Mol. Biol. 11:433-439.

Ye, X. S., S.Q. Pan, and J. Kuc. 1990. Association of pathogenesis-related proteins and activities of peroxidase, $\beta-1,3$-glucanase and chitinase with systemic induced resistance to blue mould of tobacco but not to systemic tobacco mosaic virus. Physiol. Mol. Plant Pathol, 36:523-531,

Yeomann, M.M. 1986. Plant cell culture technology, Blackwell Scientific, Oxford, U.K.

Zyprian, E. and C.I. Kado. 1990. Agrobacterium-mediated plant transformation by novel mini-T vectors in conjunction with a high-copy vir region helper plasmid. Plant Mol. Biol. 15:245-256. 